Session \# 3441

\title{
Deconstruction of an Engineering Syllabus for Information Literacy
}

\author{
Barbara Williams ${ }^{\mathrm{a}}$, Paul Blowers ${ }^{\mathrm{b}}$ \\ ${ }^{a}$ University Library \\ ${ }^{b}$ Department of Chemical and Environmental Engineering \\ The University of Arizona
}

\begin{abstract}
Information literacy skill sets provide the foundation for lifelong learning, and the desire to produce engineers with these skills has necessitated the collaboration between librarians and faculty to meaningfully integrate information literacy instruction into the engineering undergraduate curriculum. Two specific criteria of the Accreditation Board for Engineering and Technology (ABET) such as the ability to formulate problems, and knowledge of contemporary issues, rely on a student's ability to locate and synthesize information in its various formats. Developing information literacy skills will allow students to exert more control over the structuring of their own learning within and beyond the classroom.

This discourse begins by examining some of the tangible and marketable benefits of information literate engineering students. This is followed by an examination of a successful collaboration between an engineering faculty and a librarian in the instruction of undergraduate and graduate students in becoming more information savvy. More often than not, students begin their research process by "surfing the net" yet the Internet appears to skew a student's ability to discern between refereed and non-refereed materials. As faculty we have all found it disheartening to have students submit technical reports in which most of the citations are to web pages.

To highlight the need for incorporating information literacy into the engineering curriculum, we deconstruct an engineering syllabus and identify areas in several course assignments where information literacy can be interjected in a nonintrusive but highly beneficial way. We identify the components of information literacy that support and provide transferable skills to ensure that students are successful in future information seeking endeavors.
\end{abstract}

\section{Introduction}

One purpose in writing this article is to advocate for the systematic inclusion of information literacy across the undergraduate engineering curricula in instances where it naturally fits in. We contend that the development of a skill set, which integrates both lifelong learning and information literacy skills into the engineering subject curricula as a pedagogical approach to learning, and not as a peripheral add on, enhances the overall 
student learning experience. Positive student learning experiences are activities typically encouraged and measured by organizations that seek to evaluate and codify the college learning experience. Therefore, treating this skill set as an after-thought marginalizes the noble concepts of both lifelong learning and information literacy. This paper is concerned with "the characteristics of undergraduate education, which enable and encourage graduates to participate in formal and informal learning throughout their lives." Much of our discussion centers on technical strategies for transferring information literacy skills by impacting the course syllabi.

The information presented here is based in part on some of the dialogue, which transpired between a chemical and environmental engineering instructor and an engineering librarian. The conversation between the two began as a targeted campaign to fulfill the requirements of a primary job responsibility, which is to cultivate instructional partnerships with faculty, students, and researchers for the purposes of positively impacting the overall student learning experience. These instructional partnerships are normally created as a by-product of connection development activities. One aspect of connection development as defined by the University of Arizona Libraries is the cultivation of a teaching partnership between librarians and the faculty that teach in their subject areas. The creation of these instructional collaborations, are referred to by the library as "Librarian/Faculty Instructional Partnerships" and is defined as "instructional opportunities that incorporate information literacy skills as a result of the collaboration of librarians and faculty in development of the curriculum."2

These instructional partnerships are intended to create a parallel learning process by infusing information literacy with regular course work. This particular teaching methodology teaches information literacy skills using the class content in a way that makes the literacy point with out appearing contrived. Educators refer to instances where these types of opportunities naturally occur, as "teachable moments." It is during these "teachable moments" that the greatest impact can be made and felt. Research studies indicate that learning, which is directly related to real life situations where the lesson is applicable to the learner contributes to creating lasting indelible impressions and become mentally stored in such a way as to be easily retrievable. "The most effective way to educate our youth is to teach them in the context of real-life situations and real problems." 3

\section{Information literacy}

Information literacy, according to the Association of College \& Research Libraries (ACRL) "is a set of abilities requiring individuals to recognize when information is needed and then have the ability to locate, evaluate, and use effectively the needed information." "The concept of the development of a skill set that would allow engineering graduates "to engage in lifelong learning to keep abreast of changes in technology and new investigative tools for doing research" was readily accepted, in the engineering disciplines, evidenced by the warm reception the "Information Competencies for Engineering" draft received when it was circulated during the Engineering Libraries 
Divisional meeting at the American Society for Engineering Education annual conference in June of 2001.

Maneuvering through the volumes of published information currently accessible to anyone with a computer is a complex process, especially for the novice researcher. Information Literacy instruction is designed to create users capable of finding information on a given topic, analyze it, and then integrate the new information with what is known to produce learners versed in the art of extracting and synthesizing information. "If you've got a computer connected to the Internet, you've got access to a virtual universe of endless information, with just the click of a mouse. But how you navigate through that sea of information means the difference between discovery and discouragement." ${ }^{6}$ Information literacy simply shows one how to chart a course to navigate the information superhighway strategically.

\section{Lifelong learning}

The term 'lifelong learning' originated in Europe in the early 1970s'. During that same time period in the United States, the concept was primarily used in reference to learning in the work place ${ }^{8}$, and conjured up images of older adult learners engaged in leisure learning activities. Developing a shared definition of lifelong learning has been a nebulous process and it remains a term not widely understood by educators.

Currently, the term is generally defined as a continuous learning process meant to supplement one's formal education. It involves acquiring information literacy skills, and abilities that teaches one how to learn; a concept necessitated by the proliferation of information and rapid technical advancements. Central to this learning model is the belief that the responsibility for teaching learners how to learn across their lifespan is the shared responsibility of the individual and the subject specific curriculum.

Due to the rapid expansion of knowledge, there is not a lot of room in most undergraduate engineering curriculums to add additional subject content. The obvious solution is to figure out a way to teach the learner how to learn what it is they need to know by promoting self-directed learning activities. Loading the curriculum with additional content at the expense of teaching one how to learn is an outdated concept that no longer works ${ }^{9}$. This is a dilemma metaphorically represented in the proverb, "Give a man a fish and you feed him for a day. Teach a man to fish and you feed him for a lifetime." The single determining impetus towards the successful assimilation and cultivation of lifelong learning skills is an intrinsic belief that one is responsible for one's own learning.

Lifelong learning is both a process and an integrated skill set aimed at providing a learning framework based on successful learning experiences. These learning experiences can be used to create a repository of skills, both mediated by instructors and individually self-directed, that students can rely on to process knowledge. Taking responsibility for one's own learning is the first step towards self empowerment and is characteristic of an educated person. This mindset emphasizes the need to develop skills 
based on individual learning preferences, which can assist in the acquisition of individualized learning techniques.

\section{The importance of information literacy and lifelong learning to engineers}

Students who know how to find and how to ask for information experience positive learning encounters at a higher rate than their counterparts who do not have these skills. It appears that a positive learning experience generates confidence in one's ability to learn while negative experiences have the opposite effect. Possessing a basic skill set in retrieving and analyzing information facilitates all other learning. Yet, many students do not know how to ask for information as evidenced by those who approach the reference desk expecting the information provider to read over their course assignment and then determine for them what information is required.

The above behavior demonstrates a lack of sophistication in the art of extracting information. It also does not present the inquirer in the best light because it shows a lack of preparedness, initiative, and responsibility, three traits that corporate America favors. The ability to extract information succinctly is a transferable set of skills that employers appreciate and reward because it demonstrates a sense of responsibility, initiative and showcases one's capacity to solve problems. It is not the information provider's responsibility to figure out what the student is being asked for in a given assignment; that responsibility resides exclusively with the student. When a student does not understand an assignment, it is the student's responsibility to engage the instructor in a discourse until the student understands specifically what is being required. In academia this is referred to as taking responsibility for one's own learning.

The best teachers know the value of "teachable moments" a concept "consistent with current research - that instruction in information retrieval is most effective if it is course-integrated, and delivered at the time of need." ${ }^{10}$ Given the huge amount of technical information generated across the various engineering disciplines, students can develop and refine their skills in locating and analyzing information more effectively in a parallel learning process where information skill building is incorporated into their regular course work. Engineers today require a high degree of proficiency in a range of abilities outside of the traditional course content. In fact, it was in part due to the lack of information literacy skills demonstrated by new engineering graduates that so concerned the engineering industry that ABET felt prompted to include in its 2000 guidelines a requirement, requiring teaching students "to learn how to learn." 11

\section{Who is in the best position to impart these skills?}

Librarians are in a unique position to facilitate the learning of information literacy and life long learning skill sets primarily because they have always championed the concept of an educated library user. Their goals have consistently been to create independent, self-reliant learners by demonstrating information gathering techniques in a content specific context designed to reinforce desired learning outcomes, which typically means teaching literacy skills through problem-based activities. Yet, "incorporating 
information literacy across curricula, in all programs and services, and throughout the administrative life of the university, requires the collaborative efforts of faculty, librarians, and administrators." 12

\section{Deconstruction of the syllabus}

Syllabi serve many functions to different groups of users ${ }^{13}$. Students view a syllabus as a contract ${ }^{14-18}$ with the professor that describes how they should behave, what the class schedule is, and how they need to perform in order to receive a passing grade. While faculty often use the syllabus to organize their thoughts about the course, to outline course content, and to inform students in the class what is expected of them ${ }^{19}$. The syllabus is also a tool for starting a discussion between faculty and students of the course objectives that will be covered during the semester ${ }^{20}$.

For librarians, the syllabus provides an excellent opportunity to begin a discussion designed to emphasize the students' responsibility for taking ownership of understanding the syllabus content, and to be able to communicate that understanding when soliciting information to fulfill those requirements. Encouraging students to speak up and ask questions for clarification purposes, and sharing with them appropriate and inappropriate questions for information providers can accomplish this. Examples of inappropriate questions are, "Can you help me figure out what it is my professor wants me to do?" or "Do you think it would be ok to do 'this' instead of 'that' since I can't find any information on the assigned topic?" While there are no good or bad questions, some questions are appropriate and some are inappropriate depending on whom one is asking. This skill set is specifically designed to help students develop appropriate expectations since inappropriate expectations can be potentially construed as a sign of immaturity.

Information providers do a disservice to the students they intend to help when they petition the students' instructor on their behalf when problems arise regarding assignment interpretations or scarce library resources. In some cases, it is in the information provider's self-interest to do so to avoid "subject wipeout" which occurs when the nonprocrastinators get to the library first and check out all the available materials on a given topic. However, for the most part, this type of interference reinforces inappropriate expectations on the students' part. If one of the goals is to ready students for the workforce, then we must use a learning model that develops and reinforces skills that corporate America deems necessary. For information providers, the situation described above can become a "teachable moment" by engaging the student in a discussion designed to help them formulate relevant questions, which they can then use with their instructors to clarify expectations.

The syllabus is also a place where one can present meta-objectives like lifelong learning and information literacy as overarching goals that students can utilize in order to achieve mastery of the course content. Figure 1 gives an example of such a set of course content, outlining both specific and meta-objectives for the equilibrium chemical engineering thermodynamics course for junior chemical engineers at the University of Arizona. 


\section{Course Objectives:}

Upon completion of this course, students should:

1) be able to solve thermodynamics problems using both hand and computer programming techniques, building on ChEE 202 and ChEE 316

2) be able to derive working equations for the solution of practical problems in thermodynamics starting from basic principles

3) be able to compute thermodynamic properties of pure and mixed ideal and real gases

4) be able to construct phase diagrams for ideal and real mixtures of gases, liquids, and solids

5) be able to construct and use a model of phase behavior using limited experimental data for VLE and LSE

6) be able to formulate and solve chemical equilibrium calculations that may include multiple reactions

Other metaobjectives the students should be proficient at:

1) be able to comfortably organize and present group or individual material to the class

2) be able to add equilibrium thermodynamic knowledge to your existing framework of chemical engineering problem solving techniques

3) be able to identify personal difficulties during problem solving and to take corrective action

4) be able to knowledgeably think of everyday examples where equilibria are important

5) be able to search for and use information from published sources

Figure 1 - An example of syllabus course objectives highlighting both course content and meta-objectives.

Although the six course content objectives listed for this course may not appear to be related to lifelong learning or information literacy, many of them have these goals as underlying objectives. For instance, a student may be required to find a published phase diagram for a homework problem, thus meeting objective five while developing information finding skills. However, the meta-objectives listed fourth and fifth directly deal with topics that require active outside information gathering and independent learning.

Also, teaching students how and what to cite is another approach to fulfilling objective 5 -- "be able to search for and use information from published sources." Teaching students what to cite presents opportunities to teach students how to distinguish between primary sources and secondary sources. Students sometimes inappropriately quote secondary sources as fact without actually having documentation of such. For example, a student quotes from a text the phrase "at least half of the student population in this country uses the internet daily." This statement may in fact be true, but if the author does not cite the source that the statement was based on and the information does not appear to be obvious, then a librarian would encourage the student to look for a primary source to substantiate the cited statistic. 
Figure 2 is an excerpt from the first homework assignment for the second thermodynamics course for chemical engineers at the University of Arizona. Here, students are expressly asked to find some vapor-liquid equiplibria data for one binary chemical system. There are approximately 30 articles that have been published on these two chemicals either alone or in conjunction with a third substance. However, only four or five of the references actually have the published VLE data. The data will be difficult for students to find. In light of this, students have the option of fulfilling the library informational objective of learning how to search for specific information, meta-objective five from the course syllabus, by describing their search strategies and documenting the search results.

Teaching students how to think through the process of formulating effective search strategies will give them a tool they will be able to draw upon long after the class has ended. Fundamentally, it involves the ability to formulate key word searches to retrieve relevant information and requires an understanding of the search engines basic Boolean logic structure in order to be able to manipulate the database being searched. This in turn gives the class a "teachable moment" where a discussion about search strategies can be held so that all students benefit from how some strategies will or will not work in specific instances.

Another teachable moment in this context would be to provide an overview of the available print and electronic resources in a topical area. This approach is necessary in the engineering disciplines since students usually need to obtain information from multiple sources to solve a particular problem; rarely can they find what they need in one stop shopping. For example, in order to find " $\mathrm{X}$ " you might have to extrapolate data from one source in order to look up information in another source. The skill set that needs to be developed in this situation is developing information gathering and pattern recognition skills, as well as the ability to synthesize information from a number of resources.

One of the benefits of librarian-faculty collaborations is that when librarians know ahead of time the specifics of a given course, they can arrange to preview databases the library does not own that is related to the course content. The instructor can then base an assignment around the content of the database and the results of the database usefulness can form the basis for determining if the library should consider purchasing it or a similar resource. 
Such was the case when the University of Arizona Libraries previewed Knovel Engineering \& Scientific Online References. Knovel is a database consisting of engineering reference materials from popular reference handbooks, databases, and conference proceedings. Students found the information contained in the database useful to their projects, and the professors were able to conceive of ways that the resource could be specifically integrated into future courses. Students now have greater knowledge of high quality materials while faculty can assign more complex or far-reaching assignments.

In the quest to carry out connection development activities at the University of Arizona, it was discovered that librarians can aid in the fulfillment of engineering ABET criteria. Engineering faculty can reciprocate by aiding librarians in their duties by working more closely with them to develop instructional activities that use their strengths. One thing that students should always be reminded of is that there is no such thing as a 'stupid question'. A person who is afraid to ask a question or express an idea is ashamed to learn. And there is nothing shameful about learning, since "learning is simply a matter of learning how to ask questions and engaging in a search for an answer" ${ }^{\prime 21}$. We must foster a sense of inquiry and lifelong learning in our students to accomplish our goals and teach them how to ask questions.

\section{Conclusions}

To be successful in practice, engineering students need to know how to gather and solicit information for the purposes of making informed decisions and implementing assigned tasks. We have highlighted in this paper just a few instances where a continuing dialogue between librarians and engineering faculty led to "teachable moments" where students can learn how to become self-sufficient seekers of information.

\section{Citations}

1. Candy, P.C., Crebert, G., \& O'Leary, J. (1994). Developing Lifelong Learners through Undergraduate Education. National Board of Employment, Education and Training. Commissioned Report No. 28.

Canberra: Australian Government Publishing Service. (p.iii).

2. "Librarian/Faculty Instructional Partnership Definition," Retrieved March 7, 2003 from: http://dizzy.library.arizona.edu/library/teams/infolit/InfoLit2000/partnership.shtml

3. Jones, D., "Critical Thinking in an Online World", http://www.library.ucsb.edu/untangle/jones.html p3 (1996) [This is an official University of California, Santa Barbara Library web page accessed 03/03.03]

4. Association of College \& Research Libraries. Information Literacy Competency Standards for Higher Education.(Chicago: American library Association, 2000) (p.2)

5. "Information Competencies for Engineering - Draft" Circulated at the American Society for Engineering Education (ASEE) conference in June 2001

6. Library Smart - You Be the Judge! Evaluating Information for Reliability http://www.librarysmart.com/working/LSPublic/01_evaluate.asp. [C 2001 Washington State Library accessed 03/03/03]

7. Candy, P.C., Crebert, G., \& O'Leary, J. (1994). Developing Lifelong Learners through Undergraduate Education. National Board of Employment, Education and Training. Commissioned Report No. 28.

Canberra: Australian Government Publishing Service. (p.24). 
8. Candy, P.C., Crebert, G., \& O'Leary, J. (1994). Developing Lifelong Learners through Undergraduate Education. National Board of Employment, Education and Training. Commissioned Report No. 28.

Canberra: Australian Government Publishing Service. (p.22).

9. Roth, L., "Educating the Cut-and- Paste Generation", Library Journal., 124:18, p3 (1999) Database:

Academic Search Elite

10. Fullerton, A., "Instructional Development Grant Recipient Highlight Fall 1998",

http://www.adm.uwaterloo.ca/infotrac/idno8.html [Page is maintained by the_University of Waterloo Last updated November 19, 1998 - accessed 03/03/03]

11. Criteria for Accrediting Engineering Programs, Engineering Accreditation Commission, Baltimore, MD, Nov. 1, (2000).

12. Association of College \& Research Libraries. Information literacy Competency Standards for Higher Education.(Chicago: American library Association, 2000) (p.4)

13. Blowers, P., "Course Syllabus Construction: A Stitch in Time Saves Nine", Proceedings of the 2002

American Society for Engineering Education Annual Conference and Exposition, (2002).

14. Baker, R. N., "The mathematics syllabus and adult learners in community colleges" Integrating technique with content", Comm. Coll. J. Res. Pract., 25, 391-402 (2001).

15. Smith, M. F., and N. Y. Razzouk, "Improving Classroom Communication: The Case of the Course Syllabus", J. Educ. for Bus., March/April, 215-221 (1993).

16. Matejka, K. and L. B. Kurke, "Designing a Great Syllabus", Coll. Teach., 42, 115-117 (1994).

17. Eberly, M. B., S. E. Newton, and R. A. Wiggins, "The Syllabus as a Tool for Student-Centered Learning", J. Gen. Ed., 50, 56-74 (2001).

18. Becker, A. H., and S. K. Calhoon, "What Introductory Psychology Students Attend to on a Course Syllabus", Teaching of Psychol., 26, 6-11 (1999).

19. Wankat, P. C., and F. S. Oreovicz, "Chart your course", ASEE Prism, 8, 18 (1999).

20. Fernandez, E., PT 262 - Programming \& Problem Solving Syllabus, Indiana University-Purdue

University Indianapolis, (2002).

BARBARA WILLIAMS

Barbara Williams is an Assistant Librarian in the Science and Engineering Library at the University of Arizona. She received her B.A. in Psychology from Michigan State University and her MLS from Wayne State University.

\section{PAUL BLOWERS}

Paul Blowers is an Assistant Professor in the Department of Chemical and Environmental Engineering at the University of Arizona. He received his B.S. in Chemical Engineering from Michigan State University before attending the University of Illinois at Urbana-Champaign for his M.S. and Ph.D. in Chemical Engineering. In addition to educational research, his other academic research involves using quantum chemical techniques for predicting reaction rates in different environments. 